\title{
Discurso, midiatização e circulação de sentidos em relações públicas
}

Discourse, mediatization and circulation of meanings in public relations

Discurso, mediatización y circulación de sentidos en las relaciones públicas

- Doutora em Comunicação e Cultura Contemporâneas pela Universidade Federal da Bahia (UFBA).

- Mestra em Literatura e Diversidade Cultural pela Universidade Estadual de Feira de Santana (UEFS).

- Professora Titular do Curso de Bacharelado em Relações Públicas da Universidade do Estado da Bahia (Uneb).

- $\quad$ E-mail: Lidicom@yahoo.com 


\section{Resumo}

A fim de contribuir com a comunicação organizacional via estudos dos discursos e da midiatização, o artigo sugere atualizar a compreensão das relações públicas. A partir de pesquisa bibliográfica, defende que modelos funcionalistas e lineares não dão conta da complexidade dos processos comunicacionais em sociedades midiatizadas ou em vias de midiatização e conclui que, se a circulação é, por excelência, a zona de disputa e negociação de sentidos, deve ganhar relevância em trabalhos sobre gestão de conflitos entre atores sociais.

\section{PALAVRAS-CHAVE: CIRCULAÇÃO • COMUNICAÇÃO ORGANIZACIONAL・DISCURSO • MIDIATIZAÇÃO • RELAÇÕES PÚBLICAS.}

\section{Abstract}

Aiming at contributing to Organizational Communication by discourse and mediatization studies, this article seeks to update the understanding of Public Relations. Based on a bibliographic research, it argues that functional and linear models do not represent all the complexity of communication processes in mediatized societies or those in process of mediatization, and it concludes that its relevance to work on conflict management between social actors should be uplifted, since circulation is the ultimate area of dispute and negotiation of meanings.

KEYWORDS: CIRCULATION • ORGANIZATIONAL COMMUNICATION・DISCOURSE・MEDIATIZATION • PUBLIC RELATIONS.

\section{Resumen}

Para contribuir con la comunicación organizacional mediante estudios del discurso y de mediatización, este artículo pretende actualizar la comprensión acerca de las relaciones públicas. Con base en investigación bibliográfica, se argumenta que los modelos funcionalistas y lineales no bastan para abarcar la complejidad de los procesos de comunicación en sociedades mediatizadas o en proceso de mediatización y se concluye que, dado que la circulación es el área de disputa y negociación de significados por excelencia, la misma debería ganar relevancia en trabajos sobre gestión de conflictos entre actores sociales. 


\section{INTRODUÇÃO}

A base teórica funcionalista sustentou boa parte dos estudos em relações públicas (RP), os quais especulam sobre as funções organizacionais exercidas por tal atividade no sistema social. Os estudos clássicos de RP no Brasil foram dominados também pelo modelo informacional ou linear da comunicação. Tal paradigma se cristalizou a partir da Teoria Matemática da Comunicação, que tem por premissa uma comunicação intencional, iniciada pelo emissor e com um significado comum na recepção - premissa que parece estar ainda na base de muitas abordagens de RP, ao explicá-la como atividade responsável por gerenciar a comunicação entre organização/assessorado e públicos/stakeholders.

A partir de semelhante percepção, nos últimos anos muitos autores buscaram atualizar a compreensão de RP. Luiz Carlos lasbeck, por exemplo, ao elucidar como as relações públicas estão contidas no âmbito da comunicação organizacional (CO)', esclarece que "[...] os relações públicas cuidam essencialmente da qualidade do processo da comunicação nas organizações e se distribuem em áreas estratégicas nas quais é possível controlar, coordenar, supervisionar, executar e avaliar, enfim, administrar a comunicação" (2009, p. 105). Parece-nos utópico, contudo, equiparar o cuidado da qualidade do processo comunicacional à ideia de controle; assim como atribuir aos profissionais de RP o escorregadio (mas usual) objetivo de conduzir a comunicação, pelo gerenciamento de conflitos ou pela busca de equilíbrio entre os interesses da organização e dos públicos, como se fossem formas de dominar o processo comunicativo.

Ao realizar uma investigação empírica sobre $\mathrm{CO}$, analisando os discursos de duas grandes organizações (a maior instituição pública de ensino superior da Bahia - a Uneb - e a Petrobras), esbarramos em inadequações teóricas que nos levaram a problematizar terminologias comuns em RP. Se concordarmos que a atividade de RP não redunda no controle do percurso semiótico (de significação) dos discursos que tramitam entre organização e públicos, como continuar falando, por exemplo, em emissor, receptor e mensagem - conceitos que admitem causalidade linear - no contexto de contínua ressignificação dos fluxos comunicacionais? 0 presente artigo resulta das pesquisas bibliográficas então empreendidas, a partir das quais compreendemos que as reflexões teóricas sobre midiatização, circulação e discursos podem oferecer ricas contribuições aos estudos de relações públicas e comunicação organizacional, considerando a atual complexificação do ecossistema midiático, que evidencia o processo circular de produção de sentidos na intensa conectividade social.

Apresentamos a seguir, com base em pesquisa exploratória, um estudo visando ultrapassar a compreensão linear e informacional dos processos de CO e aprimorar a reflexão sobre a atividade de RP. Para tanto, dividimos o texto em duas partes. Na primeira, problematizamos a produção de sentidos em RP, tendo por base estudos dos discursos franceses e latino-americanos; e, na segunda parte, apresentamos perspectivas teóricas da midiatização e da circulação, a partir das quais discutimos os processos de circulação discursiva e a disputa de sentidos sociais na comunicação organizacional.

\section{A DISPUTA DE SENTIDOS EM RELAÇÕES PÚBLICAS}

As relações públicas, quando pensadas a partir de uma perspectiva funcionalista e informacional, têm a causalidade linear como pressuposto, ainda que descartada a unilateralidade ou a via de mão única do processo comunicativo. Fala-se em troca de informação e em busca de um significado comum, como se fosse possível transferir a mesma mensagem de uma

1 Vale destacar a diferença entre CO e RP: "[...] a primeira é antes um pensamento comunicativo, uma abstração necessária à compreensão dos fenômenos que, quando tangíveis e aparentes, podem e devem ser administrados pela segunda [...]" (lasbeck, 2009, p.106). 
consciência à outra. 0 profissional de RP, então, aparece como solucionador dos conflitos causados por distorções e ruídos da comunicação; e o planejamento estratégico é apresentado como panaceia para resolver todo confronto resultante das diferenças entre os interesses da organização e dos públicos - quando seria mais adequado, talvez, pensar o planejamento estratégico apenas como um norteador.

A partir dos estudos dos discursos sociais, entende-se que "[...] entre a produção de sentido e seu reconhecimento, entre a produção de um discurso e seus 'efeitos', não há causalidade linear" (Verón, 2004, p.83). Para Verón, a comunicação humana, e não apenas a midiática, é não linear "[...] em todos os seus níveis de funcionamento, pois é um sistema auto-organizador distante do equilíbrio" (2014, p.17). Em concordância com tal premissa e com a perspectiva de Baldissera (2009), julgamos que não há como entender a comunicação organizacional hoje senão sob a percepção da sua complexidade, sobretudo na contemporaneidade, quando é subordinada a novos regimes de discursividade. Sobre isso, Fausto Neto (2010, p.60) explica:

0 conceito de enunciação chama atenção para o fato de que o ato discursivo se constitui em um complexo trabalho, uma vez que o sujeito apropria-se da linguagem para referir-se, referir o mundo e referir o seu socius. Essa construção evidencia a natureza da comunicação - interpessoal e complexa (como a midiática) - como uma questão relacional, e não só de caráter transmissional. [...] Nestas condições, o sujeito individual ou institucional não é o mestre da atividade discursiva, mas efeito do seu funcionamento na medida em que se encontra 'constrangido' ou 'mobilizado' por uma ordem que o transcende, como algo complexo que é aquele da interdiscursividade.

No jogo de oferta e reconhecimento dos discursos, eles são apropriados e transformados em novos discursos, em um processo de semiose ${ }^{2}$ infinita. Essa natureza interdiscursiva ${ }^{3}$ ou relacional da comunicação, e não simplesmente transmissional, pode ser observada em um dos casos por nós investigados na pesquisa: o discurso da CO da Uneb - Universidade do Estado da Bahia. A maior instituição baiana de ensino superior, com 24 campi espalhados pelo interior do estado, há alguns anos edifica sua enunciação sob o ethos discursivo de universidade inclusiva e popular; com uma corporalidade negra e feminina, conforme depreendemos na análise das manifestações da marca - campanhas para os vestibulares, publicações do site institucional e postagens do Facebook. Tal imagem, contudo, foi inicialmente gerada não entre as quatro paredes da sua Assessoria de Comunicação, mas, antes, nas demandas ou práticas sociais e linguageiras dos campi. Depois de mais de uma década com cotas para negros e indígenas, além de muitas ações de docentes e discentes em torno de questões de gênero e raça, a universidade foi levada a mudar seu tradicional discurso de instituição "multicampi, gratuita e de qualidade", atualizando seu contrato de comunicação com os públicos. Logo, a enunciadora Uneb não é a mestra da atividade discursiva. Ela é constrangida por uma ordem que a transcende, a da interdiscursividade, que faz circular os signos depois por ela replicados em seus produtos de comunicação organizacional. Os discursos daí resultantes também passam, então, a fazer parte do interdiscurso, permitindo que outros discursos e práticas sociais sejam elaboradas a partir deles. A enunciação da IES como inclusiva e popular foi determinante para novos debates e reivindicações em torno de maior inclusão das minorias sociais. Como consequência, no processo seletivo 2019 houve a ampliação das cotas para quilombolas, ciganos, transexuais, travestis, transgêneros, pessoas com deficiência, transtorno do espectro autista e altas habilidades.

Como vimos, o sujeito institucional não inicia o processo comunicativo, pois, mesmo sem perceber, é constrangido por uma ordem interdiscursiva que o transcende. A dimensão interdiscursiva da circulação retira a soberania das intenções dos interlocutores, "[...] pois na medida em que os discursos se contatam, neste novo espaço, suas intenções de origem perdem força, uma vez que estão entregues a dinâmicas que fazem com que produção e recepção não as controlem bem [...]" (Fausto Neto, 2010, p.61). 0 dispositivo circulatório, dissolvendo marcas discursivas de fronteiras entre as gramáticas de 
produção e recepção, é quem define e impulsiona as operações produtoras de sentidos. Por isso, não mais associada à noção de defasagem, a circulação - "[...] transformada em lugar no qual produtores e receptores se encontram em 'jogos complexos' de oferta e reconhecimento - é nomeada como dispositivo em que se realiza o trabalho de negociação e de apropriação de sentidos, regidos por divergências e não por linearidades" (Fausto Neto, 2010, p.63).

A ideia de troca de informações entre organização e públicos é muito mais simples e, talvez, didática do que a tese de zonas de indeterminação criadas pela circulação discursiva - como defende Fausto Neto (2010), com base nos estudos de Verón. Porém, não há mais como sustentar a noção de passagem automática da produção à recepção diante de tantas disputas de narrativas e crises epistemológicas, como as que temos testemunhado recentemente no campo político, mas também no campo empresarial.

Diante da admissão da complexidade e da circularidade dos processos comunicacionais, é preferível rever as noções de "emissão" e "recepção", bem como de "mensagem", que pode produzir uma ideia de transmissão exata do significado desejado, ou substituí-la por "enunciado" ou "discurso"4. Mesmo porque entendemos a comunicação como um espaço gerador de potencialidades e não de intencionalidades. Tal concepção não é nova:

\footnotetext{
Para a Análise de Discurso, não se trata apenas de transmissão de informação, nem há essa linearidade na disposição dos elementos da comunicação, como se a mensagem resultasse de um processo assim serializado: alguém fala, refere alguma coisa, baseando-se em um código, e o receptor capta a mensagem, decodificando-a. [...] Eles estão realizando ao mesmo tempo o processo de significação e não estão separados de forma estanque. Além disso, ao invés de mensagem, o que propomos é justamente pensar aí o discurso. Desse modo, diremos que não se trata de transmissão de informação apenas, pois, no funcionamento da linguagem, que põe em relação sujeitos e sentidos afetados pela língua e pela história, temos um complexo processo de constituição desses sujeitos e produção de sentidos [...] As relações de linguagem são relações de sujeitos e de sentidos e seus efeitos são múltiplos e variados. Daí a definição de discurso: 0 discurso é efeito de sentidos entre locutores. (Orlandi, 2003, p.21)
}

Apesar de Eni Orlandi explicar a teoria de Pêcheux tendo por base a linguagem verbal, podemos englobar discursos audiovisuais na compreensão de que o processo de significação humana ou social nunca se dá de forma sequencial e linear. Entendemos a comunicação como um processo necessariamente circular e os sentidos como produzidos tanto pelo enunciador quanto pelo coenunciador - sendo o primeiro o sujeito discursivo responsável pelo dito e o segundo, o sujeito discursivo que interpreta o dito. Aquele projeta no enunciado uma imagem de si, uma imagem do outro e deixa marcas da relação entre os dois. Logo, ao enunciar, pressupõe saberes e expectativas dos seus interlocutores. Já o interlocutor/público, ao interpretar, o faz a partir do conhecimento que tem previamente sobre aquele que fala (a organização, no caso), sobre o que está sendo dito e sobre o gênero do discurso em questão. Ambos, portanto, fazem uso da memória discursiva, que é "[...] o saber discursivo que torna possível todo dizer e que retorna sob a forma do pré-construído, o já dito que está na base do dizível, sustentando cada tomada da palavra" (Orlandi, 2003, p.31).

O contexto sócio-histórico, o contexto situacional (da situação de enunciação) e o cotexto são determinantes para a produção dos efeitos de sentido. Sobre esses, Maingueneau esclarece:

O sentido não remete a um espaço fechado dependente de uma posição enunciativa absoluta, mas deve ser apreendido como circulação dissimétrica de uma posição enunciativa à outra; a identidade de um discurso coincide com a rede de interincompreensão na qual ela é capturada. Não existem, de um lado, o sentido e, de outro, certos 'mal-entendidos' contingentes na comunicação do sentido, mas, num só movimento, o sentido como mal-entendido. (Maingueneau, 2007, p.22)

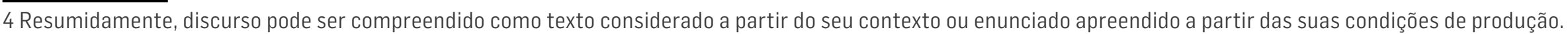


Reconhecer o sentido do discurso como mal-entendido é colocar em primeiro plano a circularidade da comunicação entre enunciador e coenunciador. Logo, o sentido não é uma unidade autônoma; mas existe tão somente no discurso. Patrick Charaudeau (2006) acentua que é problemático falar em comunicação como transmissão de informação, como se um benfeitor possibilitasse ao indivíduo não informado passar de um estado de ignorância a um estado de saber. Para ele,

\begin{abstract}
A informação não existe em si, numa exterioridade do ser humano, como podem existir certos objetos da realidade material (uma árvore, a chuva, o Sol) cuja significação, certamente, depende do olhar que o homem lança sobre esses objetos, mas cuja existência é independente da ação humana. A informação é pura enunciação. Ela constrói saber e, como todo saber, depende ao mesmo tempo do campo de conhecimentos que o circunscreve, da situação de enunciação na qual se insere e do dispositivo no qual é posta em funcionamento. (p.35)
\end{abstract}

A percepção de que há seletividade em todo e qualquer enunciado - e, logo, silenciamentos - reforça a tese da não existência da informação fora do discurso. Reflitamos um pouco mais sobre esse tópico, a partir do outro objeto por nós observado na pesquisa: os discursos da e sobre a Petrobras. Quando da operação Lava-jato (2014) e das notícias de investigação de funcionários da Petrobras, a estatal passou de orgulho a vergonha nacional em boa parte do discurso midiático, cuja cobertura do tema era explicitamente negativa e pessimista. Por outro lado, produtos de $\mathrm{CO}$ voltados aos públicos internos, como a extinta Revista Petrobras, ficaram mais de um ano sem abordar o tema e, quando o fizeram, foi com eufemismos, enquadrando os desvios como ação isolada de alguns indivíduos ou como exceção pertencente ao passado e já controlada pela instituição. No blog Fatos e Dados, destinado a responder às notícias sobre a Petrobras, o enunciador reconheceu a crise, mas procurou esclarecer os fatos, mencionando números positivos para compensar os prejuízos financeiros divulgados pela imprensa, "[...] a fim de amenizar a situação por meio da oferta de sentidos segundo os interesses da Companhia" (Machado; Barichello, 2017, p.17). Em 2015, durante o governo Dilma, o discurso do Planalto sobre a Petrobras foi marcado por um tom de confiança na sua recuperação e dava relevância a prêmios, acordos internacionais e investimentos (Machado; Barichello, 2017). Porém, nos anos seguintes, os governos Temer e Bolsonaro se apropriaram do interdiscurso sobre a corrupção da estatal e a suposta consequente diminuição dos lucros para justificar a venda de grande parte da empresa, por meio de um grande projeto de "desinvestimento" 5 . Observamos, enfim, que os campos sociais em questão, a partir de distintos lugares de fala e com variações nos modos de enunciar, buscam sempre legitimar os seus discursos por argumentos e informações como se esses falassem por si. Toda escolha enunciativa se caracteriza por aquilo que retém ou despreza, põe em evidência certos fatos deixando outros às sombras.

Com perspectivas teóricas diferentes, não são poucos os autores em RP que têm problematizado o persistente - mas falido modelo linear da comunicação. Carlos lasbeck (2009), por exemplo, entende que "não se trata de forma alguma de um processo linear e teleológico, mas de uma intensa e imbricada rede de relacionamento que produz, transforma e consome informação" (2009, p.106). Baldissera e Silva (2009) esclarecem que a comunicação organizacional inclui manifestações diversas das relações dos públicos com a organização, extrapolando o discurso estratégico e autorizado. A CO é, portanto, um "[...] processo de construção e disputa de sentidos. [...] não se restringe à fala oficial, planejada, mas se realiza sempre que um sujeito estabelecer algum tipo de relação (direta ou indiretamente) com a organização" (Baldissera; Silva, 2011, p.5). A "disputa de sentidos" tem a ver com o "conflito de interesses" (sintagma comum nos estudos de RP), mas revela maior complexidade, pois não envolve apenas interesses ou um querer conflitante com outro querer anterior ao discurso e, sim, um conjunto de compreensões, incompreensões e ressignificações que se dão em um processo circular da discursividade social.

Usar estudos dos discursos para entender a comunicação organizacional reforça ligações entre as ações comunicacionais e seu contexto, entre os enunciados e os sujeitos, modificando a forma pela qual apreendemos, nesse campo, a cultura e 0

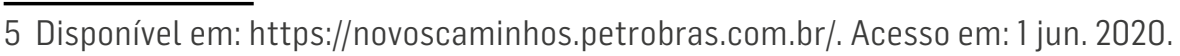


sentido. Contudo, além de teorias discursivas e semióticas, sugerimos que os estudos dos media não sejam perdidos de vista, sobretudo em tempos de releitura das relações públicas como subárea mais ligada a Negócios do que à Comunicação Social ${ }^{6}$.

\section{A MIDIATIZAÇÃO E A COMUNICAÇÃO ORGANIZACIONAL}

Com o crescente desenvolvimento tecnológico, novos fluxos comunicacionais se formam e a paisagem midiática se complexifica. As condições de produção, reconhecimento e circulação dos discursos se modificam, em razão das novas formas de o indivíduo se relacionar com o conhecimento, com outros indivíduos e com as instituições. 0 constante monitoramento organizacional, não apenas da materialização de sentidos dos públicos, mas dos concorrentes e de enunciados noticiosos ou não no ambiente digital - como depoimentos negativos de influenciadores - é uma amostra de como, atualmente, aumenta a circunferência da circulação dos discursos organizacionais. Nesse contexto, as pesquisas precisam ampliar o olhar sobre a circulação, entendida como espaço de contato entre atores marcados por batalhas de sentidos.

As mudanças de caráter, função e estrutura das instituições, em resposta à digitalização dos processos sociais e à onipresença dos media, são resultantes de um fenômeno conhecido como midiatização. Stig Hjavard (2012, p.54) explica a midiatização como a influência dos meios de comunicação na cultura e na sociedade:

\footnotetext{
Os meios de comunicação não são apenas tecnologias que as organizações, os partidos ou os indivíduos podem optar por utilizar - ou não utilizar - como bem entenderem. Uma parte significativa da influência que a mídia exerce decorre do fato de que ela se tornou uma parte integral do funcionamento das outras instituições, embora também tenha alcançado um grau de autodeterminação e autoridade que obriga essas instituições, em maior ou menor grau, a submeterem-se a sua lógica. A mídia é, ao mesmo tempo, parte do tecido da sociedade e da cultura e uma instituição independente que se interpõe entre outras instituições culturais e sociais e coordena sua interação mútua. (Hjavard, 2012, p.54)
}

As relações entre as pessoas ou entre elas e as instituições culturais e sociais, em grande medida, passaram a ser midiatizadas fenômeno ainda mais evidenciado no isolamento social causado pela pandemia da Covid-19. As organizações ficaram cada vez mais dependentes dos media e tornaram virtuais muitos dos seus protocolos, como uma forma de se adaptar às novas ambiências midiáticas. Práticas, leis e rotinas midiáticas passaram a regular outros sistemas e a própria sociedade passou a perceber a si mesma a partir do fenômeno midiático.

Ao buscar um paradigma contemporâneo a partir do qual se possa atualizar a reflexão sobre a comunicação organizacional, com base em fenômenos característicos da sociedade complexa, Daiana Stasiak (2015, p.28) conclui que o olhar teórico da midiatização responde a tal propósito; mesmo porque ele "[...] vai em direção à quebra de sentido da fórmula linear EmissorCanal-Receptor (E-C-R), característica única, por muitos anos, também nos estudos da comunicação organizacional". Processos de midiatização podem ser observados quando uma organização se apropria de lógicas e funções da mídia, por exemplo, ao lançar mão de um blog institucional, no qual explora a visada informativa e propõe tornar os fatos transparentes (como acontece com o Fatos e Dados - Petrobras), buscando a legitimação do seu dizer pela "desintermediação midiática" (Machado; Barichello, 2017). Tal concepção, contudo, não diz respeito apenas à influência do campo midiático sobre o campo organizacional, mas "[...] prevê a influência mútua entre organizações, meios de comunicação e sujeitos e reflete sobre a autonomia de cada uma dessas instâncias a partir da evolução das tecnologias" (Stasiak, 2015, p.18).

6 Em 2018, o manual da Cine-Brasil, Classificação Internacional Normalizada da Educação, ao revisar e atualizar os cursos de graduação e sequenciais do Brasil, deslocou os cursos de Relações Públicas para a área de Negócios e Administração. Disponível em: http://download.inep.gov.br/educacao_superior/censo_superior/apresentacao/2018/ Manual_Preliminar_para_a_Classificacao_dos_Cursos_Cine_Brasil_2018.pdf. Acesso em: 26 jun. 2020. 
A midiatização é explicada por Muniz Sodré (2013, p.24) como a "[...] 'mediação' social tecnologicamente exacerbada [...]", que se diferencia dos processos de mediação tradicionais, pois na midiatização impera o uso de dispositivos midiáticos para a sobrevivência cotidiana do indivíduo na sociedade. A partir da midiatização, a interação humana se transforma em tecnointeração, costumes e percepções são alterados e o modo de presença do sujeito no mundo está submetido a um novo bios - nova ecologia comunicacional. Esse ecossistema configurado pelos media, com atmosfera social própria, incide profundamente no tecido da sociedade. As instituições não têm como ignorar o que Sodré $(2013$, p. 25) chama de "quarto âmbito existencial" da tecnocultura, pois a lógica da mídia já as (co)habita, assim como aos demais atores sociais nas culturas ocidentais, ainda que eles não abandonem suas lógicas próprias.

A abordagem semioantropológica de Eliseo Verón explica o processo de midiatização como a "sequência de fenômenos mediáticos históricos que resultam de determinadas materializações da semiose, obtidas por procedimentos técnicos" (Verón, 2013, p.147). Ele ultrapassa a dimensão dos meios digitais e é considerado a partir da capacidade de semiose humana desde o paleolítico, quando houve a primeira comunicação mediada. Na medida em que há a exteriorização dos processos mentais e a materialização do sentido em um suporte, descontextualizando-o e permitindo que outros sujeitos tenham acesso a ele e o façam circular, entendemos que toda comunicação é mediada. Quanto ao fenômeno midiático, ele está atrelado à autonomia dos signos em relação à fonte, ao destino e à persistência no tempo. A midiatização, portanto, não é um fenômeno novo "[...] e tem a ver com o adensamento das faculdades cognitivas patrocinado pelo pronunciamento do midiático" (Santi, 2016, p.116). Agora, entretanto, o processo da midiatização, com sua nova ambiência e a evidente interferência nas formas de sociabilidade, desenha o ethos da humanidade contemporânea (Santi, 2016).

Vivemos na "era dos megafones digitais", conforme Carolina Terra (2011), considerando a natureza interativa da rede e suas possibilidades de mobilizações online e hashtags que, rapidamente, podem estremecer a reputação de uma organização. Os públicos podem fazer reverberar suas queixas em sites de reclamação, aos quais muitos recorrem antes de fechar um negócio, e dar visibilidade a suas próprias pautas nas redes sociais digitais, ainda que limitada pelos algoritmos. Os algoritmos regulam os regimes de circulação das postagens nas plataformas, formando bolhas em nome da conciliação e do suposto bem-estar das comunidades virtuais, mas, em tal contexto, as organizações também têm sua voz limitada, concorrendo com outras instituições, jornais, influenciadores digitais etc. para reter o interesse dos usuários da rede (economia de atenção).

Para não perderem a disputa por visibilidade e burlarem o abafamento de suas vozes pelos algoritmos, as organizações investem no refinamento de estratégias publicitárias, favorecidas pelas possibilidades de rastreamento dos dados dos usuários, que se multiplicam na internet, e de, com eles, preverem tendências e opiniões dos públicos das organizações. As informações monitoradas e coletadas, porém, demandam tratamento, agenciamento, relações, articulações. Afinal, a conectividade aumentada não espelha a expansão da comunicação. Nesse sentido, concordamos que "[...] a mediatização dialoga com a generalização das relações públicas, a partir do momento em que elas vão além da publicidade comercial e intervêm nos domínios sociais, culturais, empresariais e políticos" (Miège, 2018, p.47). Mas quem tem sua existência pautada em relacionamentos e mediação precisa saber transformar as potencialidades da efervescência conectiva atual em oportunidades de trabalho com os processos tradutórios que o momento demanda.

Carecemos de entender melhor a nova ambiência midiatizada, na qual emerge um novo modo de ser social, para que a comunicação organizacional nela se repense e atualize seus modelos operacionais. Afinal, quais os pontos de articulação possíveis, no "novo bios" tecnocultural, entre organização e públicos? Que novos protocolos comunicacionais, determinados pela sociedade midiatizada - ou "em vias de midiatização" (Fausto Neto, 2010) - determinarão a sobrevivência das instituições? Como estabelecer um contrato de comunicação com públicos que são operadores do próprio consumo e cooperadores da cena produtiva midiática, no contexto de convergência e acessibilidade facilitadas? Questões como essas podem iluminar novos caminhos para repensar as relações públicas e a comunicação organizacional na contemporaneidade. Nessa linha, o presente 
artigo, buscando contribuir para os estudos dos discursos organizacionais e dos sentidos que circulam entre instituições e públicos, mais instigou reflexões epistemológicas do que, propriamente, apresentou conclusões ou novas conceituações.

\section{CONSIDERAÇÕES FINAIS}

Vimos que o ecossistema midiático e seus múltiplos fluxos de produção, reconhecimento e circulação de sentidos têm agenciado outro modo de ser e estar no mundo, alterado as lógicas das organizações e remodelado a comunicação organizacional. Torna-se imperativa a submissão às dinâmicas midiáticas, evidenciada no constante monitoramento das redes sociais pelas empresas, nas consultorias de marketing digital, nos cursos de mídia training, entre outros formatos transformadores dos modos de informar, consultar, construir a imagem institucional e se relacionar com os públicos.

Diante da nova ambiência, que afeta também a percepção, a cognição e a ação humana, alterando as fronteiras da experiência social, advogamos pela revisão dos conceitos de relações públicas que enfatizem ainda o controle da comunicação e a dominância ou a intencionalidade do polo emissor. De modo semelhante, precisam ser atualizadas as perspectivas teóricas da comunicação organizacional que inferem efeitos sobre a recepção por meio de determinismos funcionalistas ou cuja problemática seja simplesmente técnica e instrumental. A partir dos novos regimes sócio-técnicos e da midiatização dos atos organizacionais, há de se reformular a compreensão sobre os processos de interação entre organização e públicos, e almejar, na atuação hodierna de CO ou, especificamente, de RP, o acompanhamento atento da semiose social, a construção de espaços de tradução e conexão dialógicos, mas, antes de tudo, o reconhecimento da circulação como zona de negociação ou disputa de sentidos.

\section{REFERÊNCIAS}

BALDISSERA, Rudimar. Comunicação organizacional na perspectiva da complexidade. Organicom, São Paulo, v.6, n.10/11, p.115-120, 2009.

BALDISSERA, Rudimar; SILVA, Magno Vieira da. Organizações comunicadas e ethos discursivo: imagens de si ofertadas em sites institucionais. In: CONGRESSO BRASILEIRO CIENTÍFICO DE COMUNICAÇÃO ORGANIZACIONAL E RELAÇÕES PÚBLICAS, 5., 2011, São Paulo. Anais [...]. São Paulo: Abrapcorp, 2011.

CHARAUDEAU, Patrick. Discurso das mídias. São Paulo: Contexto, 2006.

FAUSTO NETO, Antônio. As bordas da circulação. Alceu, Rio de Janeiro, v.10, n.20, p.55-69, 2010.

HJAVARD, Stig. Midiatização: teorizando a mídia como agente de mudança social e cultural. MATRIZes, São Paulo, v.5, n.2, p.53-91, 2012.

IASBECK, Luiz Carlos. Relações públicas e comunicação organizacional: o lugar do texto e do contexto. Organicom, São Paulo, v.6, n.10/11, p.103-108, 2009.

MACHADO, Jonas; BARICHELLO, Eugenia. Comunicação de crise e relações públicas: estratégias e contratos de comunicação da Petrobras, 0 Globo e Planalto em seus blogs. In: CONGRESSO BRASILEIRO DE COMUNICAÇÃO ORGANIZACIONAL E RELAÇÕES PÚBLICAS, 11., 2017, São Paulo. Anais [...]. São Paulo: Abrapcorp, 2017. p.1-23. 
MAINGUENEAU, Dominique. Discurso e análise do discurso. São Paulo: Parábola, 2015.

MAINGUENEAU, Dominique. Gênese dos discursos. Curitiba: Criar, 2007.

MIĖGE, Bernard. Para uma atualização da abordagem da mediatização das ações infocomunicacionais. In: FERREIRA, Jairo. Entre o que se diz e o que se pensa: onde está a midiatização?. Santa Maria: Facos, 2018. p.39-62.

ORLANDI, Eni. Análise de discurso: princípios e procedimentos. Campinas: Pontes, 2003.

SANTI, Vilso Junior. Mediação e midiatização: conexões e desconexões na análise comunicacional. Jundiaí: Paco, 2016.

SODRÉ, Muniz. Antropologia do espelho: uma teoria da comunicação linear e em rede. Petrópolis: Vozes, 2013.

STASIAK, Daiana. A comunicação organizacional sob a perspectiva da midiatização social: uma proposta de reflexão. In: MOREIRA, Elizabeth Huber; BRANDT, Grazielle Betina; PEREIRA, Fabiana da Costa (org.). Organização, mídia e mercado: perspectivas teóricas e empíricas de estratégias midiáticas e mercadológicas de comunicação organizacional. Santa Cruz do Sul: Edunisc, 2015. p.18-32.

TERRA, Carolina. Relações públicas na era dos megafones digitais. In: FARIAS, Luiz Alberto de (org.). Relações públicas estratégicas: técnicas, conceitos e instrumentos. São Paulo: Summus, 2011.

VERÓN, Eliseo. Fragmentos de um tecido. São Leopoldo: Unisinos, 2004.

VERÓN, Eliseo. La semiosis social 2-ideas, momentos, interpretantes. Buenos Aires: Paidos, 2013.

VERÓN, Eliseo. Teoria da midiatização: uma perspectiva semioantropológica e algumas de suas consequências. MATRIZeS, São Paulo, v.8, n.1, p.13-19, 2014.

Artigo recebido em 01.07.2020 e aprovado em 14.04.2021. 